\title{
Two reasons for not using commodity taxation in the presence of an optimal income tax
}

\author{
XAVIER RUIZ DEL PORTAL ${ }^{*}, * *$ \\ University of Lleida
}

Received: September, 2017

Accepted: February, 2019

\begin{abstract}
This paper presents two arguments in favor of the sole use of an income tax for redistribution purposes. The first is that most findings on nonlinear commodity taxation such as Mirrlees's formulae for Pareto efficiency, Seade's results on zero tax rates at the endpoints of the scale, and the Corlett-Hague tax rule only become valid under the second-order approach for the unrealistic class of utility functions that are affine with respect to ability. The second is that, for the Atkinson and Stiglitz theorem to hold, it suffices with assuming that preferences must be weakly separable in consumption and ability, a result that also remains valid with linear commodity taxation. All this relegates the use of nonlinear commodity taxes to the unlikely scenario in which, apart from non-weakly separable preferences between consumption and ability, there is a solution to the first-order approach problem.
\end{abstract}

Keywords: Nonlinear commodity taxes, second-order approach, Atkinson and Stiglitz theorem.

JEL Classification: C6, D6, D8, H2.

\section{Introduction}

Since the seminal papers of Mirrlees (1976) and Atkinson and Stiglitz (1976), most research on optimal taxation in a multi-person economy has focused on a mix where a nonlinear income tax is combined with either nonlinear or linear commodity taxes [e.g., Christiansen (1984), Edwards et al. (1994), Nava et al. (1996), and Jacobs and Boadway (2014) for the nonseparable utility case; and Laroque (2005) and Kaplow (2006), for the weakly separable case]. Extensions include, among others, considering the production side of the economy (Naito, 1999), heterogeneous preferences and endowments [Mirrlees (1976 and 1986), Cremer et al. (2001), Saez (2002) and Boadway and Pestieau (2003)], externalities

\footnotetext{
* ORCID ID: 0000-0002-6212-4346.

** Financial support from the Spanish Ministry of Economy and Competitiveness (Project ECO2012-37572) and of the Generalitat de Catalunya (Contract 2014SGR0327 and XREPP) is gratefully acknowledged.
} 
(Pirttilä and Tuomala, 1997) and the migration margin of high-skill workers (Ruiz del Portal, 2017).

The question of whether optimal commodity taxes should be uniform or not has been presented, after the formulation of the Atkinson and Stiglitz theorem (A-S theorem), in terms of whether preferences between consumption and leisure are weakly separable or not. The problem is however that, while the econometric evidence does not seem to support weak separability [Browning and Meghir (1991), Crawford et al. (2010), Gordon and Kopczuk (2014), and Pirttilä and Suoniemi (2014)], no insights are provided about the form of the non-separabilities in the utility function. In fact, none of the econometric studies presents robust evidence that, except for child-care facilities, housing expenditures and capital incomes, commodities are strongly associated with labor supply. This explains why, after the so-called Mirrlees Review (Mirrlees et al., 2011), the conventional view is that, with the exceptions mentioned, uniform commodity taxation, or even superfluous commodity taxation, should be regarded as a reasonable and important benchmark. In addition to the separability issue, this view relies on practical aspects such as administrative and compliance burdens, spillover costs, and anti-lobbying policies.

Despite this apparent consensus, a number of papers have shown nevertheless that the interest in the differential commodity tax case is still alive, whether the separability assumption on preferences is adopted or not [e.g. Revesz (2014), Nygård (2014), Jacobs and Boadway (2014), Boadway and Song (2016), Koehne (2018) or Hunt at al. (2018)]. There is also the fact that, against the lack of knowledge about non-separabilities and other arguments contained in the Mirrlees Review, some public finance authors present important objections that could to a certain extent invalidate the case for uniform taxation. ${ }^{1}$ Furthermore, the standard benchmark presents the problem of leading to recommendations that are at odds with what is observed in developed countries, where one may find a large variety of commodity taxes such as the VAT, general sales tax, and other taxes on specific goods (e.g., gasoline, tobacco, alcohol, or motor vehicles). ${ }^{2}$ Consequently, a drastic application of the uniform benchmark could go against the principle that theoretical results should be based on empirically relevant economic mechanisms, while also violating the central goal of optimal tax analysis: casting light on actual tax policy issues (Piketty and Saez, 2014).

Strangely enough there do not appear to be any studies that apply the analysis of the second-order approach to the debate about the desirability of indirect taxes. All of the research on the topic has been developed using the first-order approach, in which the constraint implying second-order conditions for incentive compatibility is left out of the analysis under the assumption that it is satisfied by the optimal solution. As a result, individual behavior appears characterized by conditions that are not valid in general for the problem posed. ${ }^{3}$ Moreover, solutions containing intervals where the second-order constraint binds are ignored under the relaxed analysis of the first-order approach. In this paper we fill the gap by exploring to what extent classical results on fully nonlinear tax systems still hold when the second-order constraint is taken into account. We will see that this task is not only of theoretical interest, but also has practical relevance because it provides us with new insights into the structure of optimal commodity taxes. 
Although there exist limitations on the use of nonlinear commodity taxation, mainly due to the non-observability of individual consumption, administrative costs, and tax avoidance by re-trading among consumers, their study is still of interest for a variety of reasons. First, at least on theoretical grounds, nonlinear tax schedules can always provide more welfare than those subject to linearity. Second, the consumption of certain important goods (e.g., water, electricity and gas) can easily be controlled through the taxpayer or the supplier, making it possible to minimize all administrative costs involved and to eliminate any arbitrage practices. Third, ration shop schedules may be successfully applied in developing countries, in the terms suggested by Gadenne (2014), as a form of nonlinear commodity taxation that is welfare-improving vis-à-vis linear commodity taxation. Fourth, under the conditions studied in Section 6 of this paper, results on nonlinear commodity taxation are also valid for linear commodity taxation.

At a methodological level, we have integrated the models of Mirrlees (1976) and Atkinson and Stiglitz (1976) so as to profit by their respective advantages. As is well-known, despite describing the same basic setup, both models differ in that, while the first treats labor as numéraire, the second selects for the same purposes an arbitrary good that is demanded by households. This explains that, while the Mirrlees (1976) framework is more suitable for studying the implementability and optimality conditions of the problem, the Atkinson and Stiglitz (1976) framework is especially aimed at exploring the structure of commodity taxes in the presence of a labor income tax. Our procedure in this context consists of considering Mirrlees' (1976) model and notation, but defining a consumption good as numéraire, thereby circumscribing labor to its role as an input that is supplied by households. This allows us to discuss the implementability and optimality issues in the terms posed by Mirrlees (1976), while making our conclusions on commodity taxation more comparable to those in the literature.

Among our findings, it has been shown that, when the solution is well-behaved, most results obtained under the first-order approach, such as Mirrlees' conditions for Pareto efficiency and Corlett and Hague's tax rule, remain in force even in intervals where the second-order constraint binds. The same applies for the zero tax rate result at both endpoints of the scale, derived by Seade (1977) and others, provided that the second-order constraint does not bind near those endpoints. The problem is nevertheless that well-behaved solutions occur almost only under the astringent assumption that utility is an affine function (i.e., composed by a linear function and a constant) as regards innate ability or skills. The need for this assumption comes from the fact that, further to satisfying the incentive compatibility constraint, the characterizing conditions for the government must be allowed to transform into those that arise under the first-order approach, as most results obtained in the literature were obtained from them. In fact, it has been through the re-derivation of such results under the second-order approach that we could identify the features of the utility functions that lead to well-behaved solutions, but the assumption is too restrictive for models of optimal taxation, as it means that, for a given amount of goods and labor, utility increases with ability at a constant rate.

As a second finding, we extend the A-S theorem on the undesirability of commodity taxes for utility functions that are not weakly separable in consumption and leisure. More 
precisely, what has been proved is that the key assumption for the A-S theorem to hold is weak separability of preferences in consumption and ability, a proviso that encompasses as a special case the assumption of weak separability in consumption and leisure. This is so under both the first- and second-order approaches, even if the government is constrained, and this should be emphasized, to linear commodity taxation. Notably, one further insight that can be drawn here is that, unlike what happens in the non-weakly separable case, a binding second-order constraint becomes equivalent to the phenomenon of bunching, thereby implying that the first- and second-order approach solutions differ only in the presence or absence of kinks in the income tax-schedule. The explanation is that, since commodity taxation turns out to be superfluous, the features of the optimal income tax coincide with those that arise in the original model of Mirrlees (1971) with one (untaxed) good.

Interestingly enough, the above two findings provide an argument against the use of commodity taxation when the government has at its disposal a nonlinear labor income tax. This is because, while the set of utility specifications suitable for the desirability of differential commodity taxation is restricted under the second-order approach to affine in ability functions, the set of utility specifications suitable for the undesirability of differential commodity taxation is extended to weakly separable in consumption and ability functions. Moreover, the extension in the latter case applies under either the first- or second-order approaches and under either linear or nonlinear tax structures. One implication is that, when preferences are nonseparable, differential commodity taxes become desirable only if there is an incentive compatible solution to the first-order approach setup, which is the scenario that has been considered by most of the studies in the area. Another implication that emerges is that econometric research should focus on the weakly separable in consumption and ability utility function, rather than (as up to now) on the weakly separable in consumption and leisure utility function.

In spite of that, two qualifications should be added to what has been said. On the one hand, this paper is limited to the basic Mirrlees-Atkinson-Stiglitz framework, not affecting therefore the various extensions that favor the use of differential commodity taxation, i.e., heterogeneous endowments and preferences, externalities, imperfect competition, administrative and compliance costs, tax evasion and avoidance, income risks and merit goods, among others. On the other hand, our finding on the need under the second-order approach of restricting utility to affine in ability functions does not modify the results in favor of differential commodity taxation achieved for linear tax schedules by an abundant literature. ${ }^{4}$

Section 2 introduces the model and problem definition. Section 3 articulates a suitable reformulation of the problem to deal with the constraint that is imposed by incentive compatibility. In Section 4, we derive the characterizing conditions that arise when the second-order constraint is taken into account. Section 5 reexamines classical rules in the literature on differential commodity taxation, focusing on ranges where the second-order constraint is binding. The A-S theorem under new requirements is studied in Section 6. Section 7 discusses how our findings affect the debate about the undesirability of differential commodity taxes in the presence of a labor income tax. Our concluding comments are presented in Section 8. Some proofs and technical details have been placed in an appendix at the end of the paper. 


\section{Model and problem}

Mirrlees' (1976) notation will be used throughout. The population is represented by a parameter $n$ distributed on $[0, N]$ according to the density function $f(n) \equiv F^{\prime}(n)>0$.

Let $X^{n}=\left\{\boldsymbol{x} \equiv\left(x_{1}, \ldots, x_{I-1}, y\right)\right.$ and $\left.z \mid \boldsymbol{x} \geq 0, z \geq 0, n>y\right\}$ define the consumption set of household $n$ in the absence of taxation, with $\left(x_{1}, \ldots, x_{I-1}\right)$ denoting consumption goods, $z$ a numéraire good, and $y$ labor. The budget set for household $n$, described in terms of taxes and subsidies in combination with producer prices, is thus given by $X^{n} \cap B$, where $B$ expresses some set imposed by the government.

The utility function $u(x, z, n) \equiv u\left(x_{1}, \ldots, x_{I-1}, y, z, n\right)$ of household $n$ is assumed to be twice differentiable and concave with respect to $\boldsymbol{x}$ and $z$, increasing in $\left(x_{1}, \ldots, x_{I-1}, z\right)$, and decreasing in $y .{ }^{5}$ Household $n$ chooses both the numéraire good $z(n)$ and an $I$-dimensional vector $\boldsymbol{x}(n)=\left(x_{1}(n), \ldots, x_{I-1}(n), y(n)\right)$ of net demands for consumption goods and labor that maximize $u(x, z, n)$ subject to the budget set for household $n$.

The optimal tax problem can be now formulated as:

Program 1.-Find the functions $\{\boldsymbol{x}(n), z(n)\}$ and the set $B$ that

$$
\begin{gathered}
\operatorname{Max} \int_{0}^{N} G(u(\boldsymbol{x}(n), z(n), n)) d F(n) \\
\text { s.t.: } \int_{0}^{N}[\boldsymbol{p} \cdot \boldsymbol{x}(n)+z(n)] d F(n) \equiv \int_{0}^{N}\left[\sum_{i=1}^{I-1} p_{i} x_{i}(n)+z(n)-w y(n)\right] d F(n)=A \\
\{\boldsymbol{x}(n), z(n)\} \text { maximizes } u(\boldsymbol{x}, z, n) \text { under }(\boldsymbol{x}, z) \in X^{n} \cap B
\end{gathered}
$$

Here, the function $G(\cdot)$ captures social preferences and satisfies $G^{\prime}(\cdot) \geq 0$ and $G^{\prime \prime}(\cdot) \leq 0$. Constraint (2) defines the restriction imposed by production possibilities, with $\left(p_{1}, \ldots, p_{I-1}\right)$ denoting producer prices based on $z$ as numéraire, $w$ the wage rate, and $A$ a per capita income that is not redistributed, so that when $A=0$ the tax policy is purely redistributive. Constraint (3) implies incentive compatibility (IC) and has already been defined. Also worth noting, we have made $\boldsymbol{p}=\left(p_{1}, \ldots, p_{I-1},-w\right)$ in the first integral of constraint (2) in order to adapt Atkinson and Stiglitz's (1976) notation conveniently.

\section{Implementability conditions}

Problem 1 seems difficult to handle unless constraint (3) is transformed into another more manageable expression with the set $B$ not appearing explicitly. In order to do so, let $v(n)$ denote the indirect utility function $u(x(n), z(n), n)$.

Mirrlees (1976, p. 334) has shown that the first- and second-order necessary conditions for consumer problem (3) are given by (subscripts denote partial derivatives): 


$$
\begin{aligned}
& v^{\prime}(n)=u_{n}(\boldsymbol{x}(n), z(n), n) \\
& \boldsymbol{s}_{n}(\boldsymbol{x}(n), z(n), n) \cdot \boldsymbol{x}^{\prime}(n) \geq 0
\end{aligned}
$$

where $s(\boldsymbol{x}, z, n) \equiv u_{x} / u_{z}$ stands for the marginal rate of substitution of $\boldsymbol{x}$ for $z$. As can be checked, $s_{n}=\left(u_{n x} / u_{z}\right)-\left(u_{n z} s / u_{z}\right)$.

The difficulty with describing (3) through conditions (4) and (5) lies in that (5) does not correspond to the type of constraint usually found in optimization theory. To solve this question, the following result will be useful.

PROPOSITION 1.-Equation (4) and inequality

$$
v^{\prime \prime}(n) \geq u_{n n}(x(n), z(n), n)
$$

are necessary conditions for a solution to problem (3).

Proof: Differentiating (4), one gets

$$
v^{\prime \prime}(n)=u_{n n}+u_{z} \boldsymbol{s}_{n} \cdot \boldsymbol{x}^{\prime}(n)
$$

where we have used the fact that (4) is equivalent to $u_{x} \cdot x^{\prime}(n)+u_{z} \cdot z^{\prime}(n)=0$. Since $u_{z}>0$, equation (7) shows that (6) in turn is equivalent to (5).

Now, consider the following calculations from $v=u(\boldsymbol{x}, z, n)$ :

$$
z=\zeta(\boldsymbol{x}, v, n) \quad \zeta_{x}=-\frac{u_{X}}{u_{z}} \equiv-\boldsymbol{s} \quad \zeta_{v}=\frac{1}{u_{z}}
$$

We want to express Program 1, therefore our optimal tax problem, as

Program 2.-Find the solution $\{\boldsymbol{x}(\mathrm{n}), v(n)\}$ that maximizes $\int_{0}^{N} G(v(n)) d F(n)$ subject to

$$
\begin{aligned}
\int_{0}^{N}[\boldsymbol{p} \cdot \boldsymbol{x}(n)+\zeta(\boldsymbol{x}(n), v(n), n)] d F(n) & \equiv \int_{0}^{N}\left[\sum_{i=1}^{I-1} p_{i} x_{i}(n)+\zeta(\boldsymbol{x}(n), v(n), n)-w y(n)\right] d F(n)=A \\
v^{\prime}(n) & =u_{n}(\boldsymbol{x}(n), \zeta(\boldsymbol{x}(n), v(n), n), n) \\
v^{\prime \prime}(n) & \geq u_{n n}(\boldsymbol{x}(n), \zeta(\boldsymbol{x}(n), v(n), n), n)
\end{aligned}
$$

Note that constraints (9), (10), and (11) are none others than conditions (2), (4), and (6) above, after substitution of the calculations in (8).

Program 1 still cannot be replaced by Program 2 because conditions (4) and (6), despite being necessary, fail to be sufficient to solve problem (3). Even so, we recall that Mirrlees (1976, p. 335) has shown that (4) in conjunction with the condition 


$$
\boldsymbol{s}_{m}(\boldsymbol{x}(n), z(n), m) \cdot \boldsymbol{x}^{\prime}(n) \geq 0, \text { all } m, n
$$

is sufficient for constraint (3) to be satisfied. Apart from this, we will use the fact that, as can be checked (see also Mirrlees 1986, pp. 1236-1237), proviso (12) is equivalent to

$$
\frac{d}{d n} u_{m}(x(n), z(n), m) \geq 0, \text { all } m, n
$$

\section{Optimality conditions}

The necessary conditions for Program 1 can now be formulated by means of the necessary conditions for Program 2.

PROPOSITION 2.-If $\{\boldsymbol{x}(n), z(n)\}$ is a solution to the optimal tax problem satisfying (13), then it also satisfies (4) and (6) and there is a parameter $\lambda \geq 0$, together with functions $\mu(n)$ and $\iota(n) \geq 0$ such that

$$
\begin{aligned}
& \lambda(\boldsymbol{s}-\boldsymbol{p}) f(n)-\psi(n) \cdot u_{z} s_{n}+\iota(n) \cdot\left(u_{n n x}-u_{n n z} \cdot \boldsymbol{s}\right)=0 ; \quad \psi(n)=\mu(n)+\iota^{\prime}(n) \\
& \mu(n)=\int_{0}^{n}\left\{G^{\prime}(v(m))-\frac{\lambda+S(m) / f(m)}{u_{z}}\right\} \cdot \exp \cdot\left(\int_{n}^{m} \frac{u_{k z}}{u_{z}} d k\right) d F(m) ; \quad \mu(N)=0
\end{aligned}
$$

where $S(n) \equiv \iota^{\prime}(n) u_{n z}+\iota(n) u_{m z}$.

If $n$ does not belong to an interval where $v^{\prime \prime}(n)=u_{n n}$, then $S(n)=0$ and:

$$
\lambda(\boldsymbol{s}-\boldsymbol{p}) f(n)-\mu(n) \cdot u_{z} \boldsymbol{s}_{n}=0
$$

Proof: See the Appendix.

Proposition 2 characterizes both the first- and second-order approach solutions to the optimal nonlinear tax problem. Under the first-order approach, $\iota(n)=0$ and $\iota^{\prime}(n)=0$ for all $n$ so that (14), (15), and (16) reduce to conditions (34), (35), and (42) in Mirrlees (1976, p. 336). Consequently, our characterization differs from the standard one in that, due to the possibility of a non-zero multiplier $\iota(n)$, condition (16) may fail to hold on ranges where constraint (11) is binding.

Conditions (14), (15), and (16) invite us therefore to reexamine those findings in the literature, such as the Corlett and Hague rule or the A-S theorem, which could be qualified as general guidelines for commodity taxation, to check whether they hold when, instead of (16), the relevant condition is (14). The difficulty lies in that (13) involves an endogenous requirement that cannot be guaranteed to hold without imposing new restrictions on the exogenous objects of the problem. A second difficulty comes from the fact that the term $\iota(n) \cdot\left(u_{n n x}-u_{n n z} \cdot s\right)$ is absent in condition (16), from which the mentioned findings were originally derived. For these 
reasons, in the next two sections we will consider different assumptions on preferences that ensure both the fulfillment of (13) and the equivalence of (14) to condition

$$
\lambda(\boldsymbol{s}-\boldsymbol{p}) f(n)-\psi(n) \cdot u_{z} \boldsymbol{s}_{n}=0 ; \quad \psi(n)=\mu(n)+\iota^{\prime}(n)
$$

Note that (17) presents the advantage of only differing from (16) in that, instead of the multiplier $\mu(n)$ it has $\psi(n)$. We will profit by this circumstance.

\section{Optimal rules for differential commodity taxation}

Consider the following specification of utility: ${ }^{6}$

Assumption (a).- - $u(\boldsymbol{x}, z, n) \equiv V(g(\boldsymbol{x}, z), n)+X(\boldsymbol{x}, z) ; V_{n g} \geq 0$.

For $X(\boldsymbol{x}, z)>0$, assumption (a) means that preferences are nonseparable in consumption and leisure. The second part of (a) is a standard Mirrlees-Spence single-crossing condition.

PROPOSITION 3.-Under assumption (a), conditions (4) and (6) together ensure that inequality (13) is satisfied.

Proof: See the Appendix.

Proposition 3 implies that the solution to Program 2 satisfies inequality (13) and, therefore, is the solution to the optimal tax problem. However, Proposition 3 is not yet sufficient to guarantee that the term $\iota(n) \cdot\left(u_{n n x}-u_{n n z} \cdot \boldsymbol{s}\right)$ vanishes in (14). Because of this, we will simplify assumption (a) in the way described below.

Assumption $(b) \cdot-u(\boldsymbol{x}, z, n) \equiv U(\boldsymbol{x}, z) \cdot n+X(\boldsymbol{x}, z)$

This special case of assumption (a) implies that preferences are affine with respect to ability. Or in other words, for a given bundle $\{\boldsymbol{x}, \boldsymbol{z}\}$, utility at each ability level increases at a constant rate that is precisely equal to $U(x, z)$. A consequence of this is that the indirect utility function $v(n)$ is convex, by condition (6).

An example of utility function satisfying (b) is that of a linear in the type and quasi-linear in the transfer function $U(\boldsymbol{x}) \cdot n-z$ used in Rochet (1987) to get an allocation rule for IC within multidimensional environments. When $n$ is restricted to be one-dimensional, assumption (b) clearly allows for a more general structure of preferences.

From now on, it is supposed that the set $X^{n} \cap B$ adopts the familiar form

$$
\boldsymbol{p} \cdot \boldsymbol{x}+\boldsymbol{t}(\boldsymbol{x})+z \equiv \sum_{i=1}^{I-1}\left[p_{i} x_{i}+t_{i}\left(x_{i}\right)\right]+z-w y+T(y)=0
$$


for $\boldsymbol{t}(\boldsymbol{x}) \equiv\left(t_{1}\left(x_{1}\right), \ldots, t_{I-1}\left(x_{I-1}\right), T(y)\right)$, the function $t_{i}\left(x_{i}\right)$ denoting a nonlinear tax on good $i=1,2, \ldots, I-1$ and $T(y)$ a nonlinear income tax.

Let $\tau_{i}$ and $T^{\prime}$ stand for the corresponding marginal tax rates. Substituting the first-order condition for IC $s_{i}=p_{i}+\tau_{i}$ into (17) yields

$$
\tau_{i}=\frac{\sigma(n)}{f(n)} \frac{\partial s_{i}}{\partial n} ; \quad \sigma(n)=\psi(n) \cdot \frac{u_{Z}}{\lambda}
$$

for $i=1,2, \ldots, I-1$. If $\tau_{i} \geq 0$, formula (19) says that marginal taxes ought to be greater on those goods whose $s_{i}$ increases with $n$ and therefore those that are preferred by the more skilled individuals. Note that the result concerns, precisely, the great majority of goods.

As another result, dividing by $s_{i}$ and $s_{j}$ in (19) evaluated for goods $i$ and $j$, one gets

$$
\frac{\tau_{i}}{s_{i}}-\frac{\tau_{j}}{s_{j}}=\frac{\sigma(n)}{f(n)} \cdot \frac{\partial}{\partial n} \log \left(\frac{s_{i}}{s_{j}}\right) ; \quad \sigma(n)=\psi(n) \cdot \frac{u_{z}}{\lambda}
$$

This formula indicates that the effect of a change in the ability level is what determines which good should be taxed more heavily.

Similarly, dividing equation (17) for two different commodities $i$ and $j$, one obtains after using the first-order conditions for IC

$$
\frac{\tau_{i}}{\tau_{j}}=\frac{\partial s_{i} / \partial n}{\partial s_{j} / \partial n} \quad i, j=1,2, \ldots, I-1
$$

Whether (21) holds does not depend on the welfare criterion adopted or on the form of the density function. Consequently, it can be understood as a condition for Pareto-efficiency by reference solely to the way the indifference curves vary with $n$. If (21) is violated, it means that there is another tax system that would leave everyone better off.

Altogether, formulae (19)-(21) imply that all taxation rules in Mirrlees (1976) are also valid under the extended approach, provided it is assumed that preferences satisfy assumption (b). The difference between (19)-(21) and Mirrlees' equations (36)-(39) is that, despite assuming (b), we do not suppose that $\iota^{\prime}(n)=0$ in the definition of $\sigma(h)$.

Regarding the zero tax-rate result at the top and bottom of the skill distribution, derived for the many commodities case by Seade (1977) under the first-order approach, its validity can still be established from (17), though only limited to the case that constraint (11) does not bind locally. To see the point in terms of equation (19), note that $\tau_{i}$ will always tend to zero as $\sigma(n)$ tends to zero, provided the assumptions in Seade (1977, p. 18) are met and no bunching in $\boldsymbol{x}(n)$ and $z(n)$ exists near $n=\{0, N\}$. Under the first-order approach we have $\psi(n)=\mu(n)$ and $B(n)=0$ so that, by (15), $\psi(n)$ and therefore also $\sigma(n)$ will tend to zero as $n$ approaches 0 or $N$. But this is not what necessarily happens when constraint (11) is taken into account, since the possibility $\iota^{\prime}(n) \neq 0$ in the definition of $\psi(n)$ cannot be ruled out in the relevant domain, in 
which case $\sigma(n)$ may not vanish as $n$ approaches 0 or $N$. This explains precisely why Seade (1977, p. 221) assumed that the second-order condition for IC was satisfied.

Apart from Mirrlees' and Seade's tax rules, there is another important result in the literature that emerges from equation (17). In this respect, Jacobs and Boadway (2013) have demonstrated that optimal marginal tax rates in (19) can be interpreted as the analogue of the Corlett-Hague rule for the case of heterogeneously skilled households and nonlinear taxes. Thus, following their analysis, let $u(\boldsymbol{x}, z, n)=a\left(x_{1}, \ldots, x_{I-1}, z, l\right)$ where $l=y / n$ stands for hours of work. If $\xi_{x_{l} l}=-a \cdot a_{x_{l} l} / a_{x_{i}} a_{l}$ denotes the Hicksian partial elasticity of complementarity between $i$ and $l$, and $\xi_{z l}=-a \cdot a_{z l} / a_{z} a_{l}$ the Hicksian partial elasticity of complementarity between $z$ and $l$, formula (19) can then be expressed as

$$
\tau_{i}=\frac{\sigma(n)}{f(n)} a_{x_{i}} \omega_{l} \cdot\left(\xi_{z l}-\xi_{i l}\right) ; \quad \sigma(n)=\psi(n) \cdot \frac{a_{z}}{\lambda}
$$

For $\omega_{l}=a_{i} l / a$ depicting the share of $l$ in utility, condition (22) captures Corlett and Hague's (1953) rule of taxing leisure complements while subsidizing labor complements. This can be seen by noting that, if $\xi_{z l}-\xi_{i l}<0(>0)$, the good $i$ is more (less) complementary with labor than the numéraire $z$, thereby implying the desirability (relatively to the numéraire $z)$ of a marginal subsidy (tax) on $i$.

\section{The A-S theorem without weak separability in goods and leisure}

We saw in the preceding sections that for differential commodity taxation to be optimal under the second-order approach it is not enough that, as in the first-order approach, weak-separability is violated. The violation has to be accompanied by a specific type of preferences that ensures the existence of a well-behaved solution.

By contrast, in Ruiz del Portal (2012-c) it was shown that weak-separability is enough for the A-S theorem to hold under the second-order approach. In fact, the A-S theorem proved to apply provided that the following (weaker) condition on preferences is met: ing in $n$.

Assumption $(c) .-u(\boldsymbol{x}, z, y / n) \equiv V(g(\boldsymbol{x}, z), y / n) ; V_{g}>0, V_{l}<0, l=y / n$ and $V_{l} / V_{g}$ increas-

Note that the utility function $V\left(h\left(x_{1}, \ldots, x_{I-1}, z\right), y / n\right)$ studied in Atkinson and Stiglitz (1976) represents a special case, given that its sub-utility function $h(\cdot)$ fails to contain the outcome variable $x_{l} \equiv y$.

It is also worth emphasizing that, since the marginal rate of substitution $g_{x i} / g_{x j}$ for any two goods $i$ and $j$ is independent of $n$ but not of $y$, preferences in assumption (c) are just weakly separable in consumption and ability, although not in consumption and labor income. Clearly, the last implies that $V(g(\boldsymbol{x}, z), y / n)$ fails, too, to be weakly separable regarding labor time $l$, or equivalently leisure time $1-l$, unlike in Atkinson and Stiglitz (1976). 
The following assumption allows for a more general form of the dependence of utility on $n$, in the sense that labor time, computed as a function of the amount of labor income and productivity $l(y, n)$, may not respond to the specification $y / n$ :

Assumption $(d) .-u(\boldsymbol{x}, z, n) \equiv V(g(\boldsymbol{x}, z), y, n) ; V_{g}>0$ and $V_{y} / V_{g}$ increasing in $n$.

Just as in the case of assumption (c), the second part of assumption (d) involves a single-crossing property.

The next proposition allows expressing Program 1 in terms of Program 2, provided preferences satisfy assumption (d).

PROPOSITION 4.-Under assumption (d), conditions (4) and (6) together ensure that inequality (13) is satisfied. Furthermore, (6) becomes equivalent to the condition

$$
y^{\prime}(n) \geq 0
$$

Proof: See the Appendix.

The second part of Proposition 4 implies that, unlike under assumptions (a) or (b), under assumption (d) a binding second-order constraint amounts to the existence of bunching.? The phenomenon of bunching is generally understood to be related to the impossibility of a perfect discrimination between agents through the tax schedule because of the presence of corners or kinks. Under these circumstances, first-order conditions for IC are not fully informative and one has to further consider the second-order conditions for IC, here represented by (23).

PROPOSITION 5.-If assumption (d) holds, then $\tau_{i}=0, i=1,2, \ldots, I-1$, so that commodity taxation becomes superfluous.

Proof: Under assumption (d), we have $u_{n n x}-u_{n n z} \cdot s=0$ in condition (14) for $i=1,2, \ldots$, $I-1$. Since $\boldsymbol{s}_{n}=0$ for $i=1,2, \ldots, I-1$, the result trivially follows from condition (17).

\section{REMARK 1}

The optimal labor income tax is characterized by the following formula

$$
T^{\prime}(y)=\frac{\mu(n) \cdot u_{z} \partial s_{I} / \partial n+\rho(n)}{\lambda f(n)}
$$

for $\mu(n)$ and $\lambda$ as in Proposition 2 and $\rho(n) \geq 0$ Moreover, $\rho(n)=0$ on intervals where $y^{\prime}(n)>0$.

Proof: Formula (24) is obtained using (23) instead of (11) in Program 2. This yields, after proceeding in identical terms as for the derivation in the Appendix of Proposition 2, a simplified version of (14) for $i=I$ which leads to (24) after considering the first-order condition for IC: $-s_{l}=w-T^{\prime}(y)$. 


\section{REMARK 2}

If the utility function in assumption (d) takes this form $u(\boldsymbol{x}, z, n) \equiv V\left(g(\boldsymbol{x}, z), x_{j+1}, \ldots, x_{I-1}, y\right.$, $n)$, other things being equal, taxation is only superfluous concerning commodities $\left(x_{1}, x_{2}, \ldots, x_{j}\right)$.

\section{REMARK 3}

Results in Proposition 5 (and Remarks 1 and 2) also obtain if the government is constrained to use linear excise taxation.

Proposition 5 shows that commodity taxation is useless, not only when preferences are weakly separable in consumption and leisure, but also in the more general case of assumption (d). This generalization of the A-S theorem, being derived from condition (14), comes in force under both the second- and first-order approaches.

Concerning Remark 1, formula (24) only differs from the income tax formula in Mirrlees (1971) in that we have $I-1$ consumption goods in addition to the numéraire $z$. Note in this respect that the first-order approach corresponds to the case in which $y(n)$ is strictly increasing and $\rho(n)$ vanishes everywhere. However, when $\rho(n)>0$ on some ranges of $n$, this means by Proposition 4 that the optimal labor income tax exhibits kinks at points where marginal tax rates jump and, for this reason, using a differentiable tax schedule would lead us to a sub-optimal solution.

Remark 2 generalizes Proposition 5 in the terms first suggested by Mirrlees (1976, p. 338). The result easily arises after following identical steps to those done in the proof of Propositions 4 and 5 for the new structure of preferences.

As for Remark 3, it derives from Proposition 5 because if $\tau_{i}=0$, this means that $t_{i}\left(x_{i}\right)$ is linear, namely with the same rate for all individuals. Since the solution characterized by conditions (14), (15), and (16) is optimal for nonlinear commodity taxation, and implementable with linear commodity taxation, it must also be optimal when the government is constrained to using linear commodity taxation. ${ }^{8}$

Jacobs and Boadway (2014, Proposition 1) have shown that, contrary to the impression left by the literature, ${ }^{9}$ the allocation described by the optimality conditions (14), (15), and (16) cannot be implemented using linear commodity taxes, unless there exist weakly separable preferences between consumption and leisure. By contrast, we have seen by following their reasoning that the marginal tax rates implied by such conditions can be interpreted as linear commodity tax rates (with a zero marginal rate) in cases where preferences fail to be weakly separable in consumption and leisure, as long as they come to be weakly separable in consumption and ability.

\section{On the desirability of commodity taxes}

Mirrlees (1976, p. 335) alludes implicitly to the analysis of the second-order approach at the end of the following paragraph [Recall that, by equation (8), $\boldsymbol{s}_{n} \cdot \boldsymbol{x}^{\prime}(n)=0$ is equivalent 
to $\left.v^{\prime \prime}(n)=u_{n n}(\boldsymbol{x}(n), z(n), n)\right]:$ "In the many commodities case we can replace the consumer constraint (18) by the weaker condition (21). If the solution of that problem satisfies (28), then it is a solution of the basic problem. This gives us an easy check on a computed solution, but it is perfectly possible that $\boldsymbol{s}_{n} \cdot \boldsymbol{x}^{\prime}(n)$ will vanish for certain ranges of $n$ in the optimum. In that case a more detailed analysis than the one below would be required."

Since conditions (18), (21), and (28) in the first part of the paragraph coincide with our equations (3), (4), and (12), it is clear that what Mirrlees (1976) suggests here is to resort to the second-order approach (i.e., to the "more detailed analysis") only in the absence of solution to the first-order approach problem. This line of priority combined with our analysis above leads to two different scenarios concerning the optimal nonlinear tax problem. The first is when the solution to the relaxed equation (16) satisfies $v^{\prime \prime}(n)-u_{n n}(x(n), z(n), n)>0$ everywhere. In this case, which is the one generally found in the literature, the response to the debate on the desirability of commodity taxation is given by the response to the question of whether or not individual preferences satisfy the weak separability property between consumption and leisure or, more generally, between consumption and ability.

The second scenario arises when the optimal solution involves $v^{\prime \prime}(n)-u_{n n}(\boldsymbol{x}(n), z(n)$, $n)=0$ on some intervals and, for this reason, instead of (16), the characterizing condition is (14). In that case, things get more complicated when preferences are nonseparable because the analysis must be restricted, as was observed, to utility functions that satisfy assumption (a) in order to implement IC constraint (3). Even so, we saw that assumption (a) does not suffice to ensure the classical rules in Mirrlees (1976), Seade (1977), and Corlett and Hague (1953) on differential commodity taxation hold, and it was necessary to further consider the stronger assumption (b) to eliminate the term $\iota(n) \cdot\left(u_{n n x}+u_{n n z} \cdot s\right)$ in (14). In the end, the result was disappointing because assumption (b) is quite restrictive, except for problems with multidimensional characteristics (e.g., Rochet and Choné, 1998, or Hartline, 2012).

By contrast, in the presence of separabilities between consumption and leisure, no further assumptions have been proved to be required for the A-S theorem to hold under the second-order approach, a result that also applies for linear indirect taxation and weak separability of preferences between consumption and ability. These facts, together with the stringent requirement in assumption (b), go clearly in the opposite direction to using commodity taxation for redistribution purposes when there is an optimal income tax. Note here that, while our findings on the second-order approach restrict the set of solutions for differential commodity taxes, our findings on the A-S theorem expand the set of solutions for superfluous commodity taxes, thereby making a case for using an income tax alone.

\section{Concluding comments}

Recent years have witnessed the appearance of several studies proposing that indirect taxes should be uniform and that distributional concerns should be left exclusively to income taxation and welfare benefits [Mirrlees et al. (2011), European Commission (2013) and International Monetary Fund (2014)]. Our analysis supports this stream of research, both by 
showing that the conditions needed under the second-order approach for optimal differential commodity taxation are much stronger than expected, and by extending the A-S theorem to utility functions nonseparable in consumption and ability.

As a result of these findings, the role of nonlinear commodity taxation in redistribution is limited to the situation in which the following two requirements are simultaneously met: 1) Individual preferences are non-weakly separable in consumption and ability;2) There is a solution to the first-order approach problem. If the first requirement is violated, commodity taxation turns out to be superfluous. If the second, the structure of preferences needed for the second-order approach conditions to hold becomes more restrictive and unrealistic than that leading to the undesirability of commodity taxation.

To end with, econometric research should clarify the empirical validity of the assumptions considered in this paper and, in particular, the likelihood of separabilities between consumption and ability in the population. Having said this, we tend to be skeptical about finding realistic nonseparable utility functions that favor the use of nonlinear commodity taxation under the second-order approach since, as our analysis has shown, the prerequisites for a well-behaved solution, in the terms described in section 5 above, prove to be too demanding. 


\section{Appendix}

\section{Proof of Proposition 2}

Let constraint (11) be expressed through the set of conditions: $u_{n}=B(n), B^{\prime}(n)=b(n)$ and $b(n)-u_{n n} \geq 0$ with $B(n)$ and $b(n)$ operating as auxiliary variables. Introducing multipliers $\lambda>0, \mu(n), \pi(n), \eta(n)$, and $\iota(n)$ for constraints (9), (10) and the set of conditions derived from (11), we form the Lagrangian for Program 2 as

$$
\begin{aligned}
L= & \int_{0}^{N} G(v) f d n-\lambda \int_{0}^{N}(\zeta+\boldsymbol{p} \cdot \boldsymbol{x}) f d n+\int_{0}^{N} \mu \cdot\left[v^{\prime}(n)-u_{n}\right] d n \\
& -\int_{0}^{N} \pi \cdot\left(u_{n}-B\right) d n+\int_{0}^{N} \eta \cdot\left[B^{\prime}(n)-b\right] d n+\int_{0}^{N} \iota \cdot\left(b-u_{n n}\right) \cdot d n
\end{aligned}
$$

Then, after integrating by parts the terms $\mu^{\cdot} v^{\prime}$ and $\eta \cdot B^{\prime}$ in $L$, and setting to zero their derivatives with respect to $\boldsymbol{x}, v, v(n), v(0), B, b, B(N)$ and $B(0)$, equations (14) and (15) together with condition $\iota^{\prime}(n)=\pi(n)$ are easily obtained after noting that $\left(\partial u_{n} / \partial \boldsymbol{x}\right)=u_{z} \boldsymbol{s}_{n}$. Concerning the second part of the proposition, it stems from the complementary slackness condition $\iota \cdot\left(b-u_{n n}\right)=0, \iota \geq 0$, which implies $\iota(n)=0$ where $v^{\prime \prime}(\mathrm{n})>u_{n n}$.

\section{Proof of Proposition 3}

Underassumption(a), wehave $u_{n}(\boldsymbol{x}(n), z(n), n) \equiv V_{n}(g(\boldsymbol{x}(n), z(n)), n)$ and $u_{m}(\boldsymbol{x}(n), z(n), m) \equiv$ $V_{m}(g(x(n), z(n)), m)$. Therefore,

$$
\begin{gathered}
v^{\prime \prime}(n)=\frac{d}{d n} u_{n}(\boldsymbol{x}(n), z(n),(n)) \equiv V_{n g} \frac{d}{d n} g(\boldsymbol{x}(n), z(n))+V_{n n} \\
\frac{\partial}{\partial n} u_{m}(\boldsymbol{x}(n), z(n), m) \equiv V_{m g}(g(\boldsymbol{x}(n), z(n)), m) \frac{d}{d n} g(\boldsymbol{x}(n), z(n))
\end{gathered}
$$

where we have used condition (4) for the first equality in A-(2). By condition (6) we must have $v^{\prime \prime}(n)-V_{n n} \geq 0$ in A-(2) and consequently $(d / d n) g(\boldsymbol{x}(n), z(n)) \geq 0$, since $V_{n g} \geq 0$ by the single-crossing property in the second part of assumption (a). This means that (13) is satisfied because, again by the single-crossing property, $V_{m g}(g(\boldsymbol{x}(n), z(n), m) \geq 0$ in A-(3).

\section{Proof of Proposition 4}

By the first part of assumption (d), the IC condition (3) can be expressed as

$$
V(g(n), y(n), n) \geq V(g(m), y(m), n), \text { all } n, n
$$

where $g(n)=g(\boldsymbol{x}(n), z(n))$ and $g(m)=g(\boldsymbol{x}(m), z(m))$. 
This means that conditions (4), (6), and (13) adopt these forms:

$$
\begin{aligned}
& v^{\prime}(n)=V_{n}(g(n), y(n), n) \\
& v^{\prime \prime}(n) \geq V_{n n}(g(n), y(n), n) \\
& \frac{d}{d n} V_{m}(g(n), y(n), m) \geq 0, \text { all } m, n
\end{aligned}
$$

A-(6) together with A-(5) implies that condition (6) reduces in this case to

$$
y^{\prime}(n) \cdot V_{g} \frac{\partial}{\partial n}\left(\frac{V_{y}(g(n), y(n), n)}{V_{g}(g(n), y(n), n)}\right) \geq 0, \text { all } n
$$

where it has been used the fact that, by condition (4), we must have $V_{g} g^{\prime}(n)+V_{y} y^{\prime}(n)=0$ in the present case.

Since $V_{g} \geq 0$ it follows by the single-crossing property in the second part of assumption (d) that A-(8) holds if and only if $y^{\prime}(n) \geq 0$. This, in combination again with the single-crossing property, leads to

$$
y^{\prime}(n) \cdot V_{g} \frac{\partial}{\partial m}\left(\frac{V_{y}(g(n), y(n), m)}{V_{g}(g(n), y(n), m)}\right) \geq 0, \text { all } m, n
$$

This proves that (13) is satisfied, after noting that A-(9) is nothing other than A-(7). 


\section{Notes}

1. An example is Stern (1990, p. 97) when pointing out: "Whilst we may have limited knowledge of price elasticities, we do know that different goods are consumed by the rich and the poor. The poor in developing countries consume very little of air conditioners and private cars, for example. We know further that the direct tax and transfer instruments are generally weak and far from universal. On this basis, and in accordance with the theory, there are therefore strong distributional grounds for higher taxes on goods consumed by the rich. Second, it is not clear that ignorance implies uniformity. Our ignorance, one supposes, is such that there are a number of null hypotheses which we cannot convincingly reject and it is not clear that uniformity should occupy centre stage. Further there are some things on which our ignorance may not be overwhelming. We might, for example, be happier with the hypothesis that the complementarity of tinned beans with leisure is less than that for golf clubs with leisure than we would with the null hypothesis that the two compensated cross-elasticities are equal. This, together with the distributional arguments, might help explain why in most countries the tax rate on food is less high than that on golf clubs."

Similarly, Boadway (2012, pp. 1154-1155) states in connection with the Pareto improving tax reform argument used in the Mirrlees Review: "It relies heavily on the income-specific tax adjustments being undertaken as part of the commodity tax reform. If they are not undertaken, the result would be convincing only if one subscribed to the hypothetical compensation criterion of Little (1957) or Coate (2000) where by a change is judged to be worth undertaking if the gainers could compensate the losers. Moreover, if the income tax is not fully optimized for some reasons and income tax reform is ruled out, preferential tax treatment of necessities can be welfare improving [...] if a substantial number of low-income persons are not in the labour force, complementarity with leisure loses its policy relevancy. In these circumstances, preferential VAT treatment of necessities has more justification."

2. In fact, the general tendency is, and this must be stressed, to increase the significance of indirect taxation in the overall fiscal system.

3. Mirrlees $(1975,1999)$ was the first to observe that this procedure may fail to provide a global optimum.

4. Under linear commodity taxation, the second-order approach only makes sense in connection with labor earnings, since it is only to them that the second-order constraint applies. See Jacobs and Boadway (2014, footnote 5).

5. Note that this is equivalent to writing $n-y$ for leisure and assuming that utility is increasing in leisure. In most of his work Mirrlees (1976) considers that the numéraire $z$ is labor, so that $z$ should be a negative number, being supplied by households, not demanded. Instead, we have selected a non-numéraire good $y$ as labor so as to follow the procedure most widely used in the literature (e.g. Atkinson and Stiglitz, 1976, Kaplow, 2006 or Jacobs and Boadway, 2014).

6. Various utility functions of this kind and their IC properties are discussed in Ruiz del Portal (2012-a, 2012-b).

7. This is a well-known feature of the two goods model (or $I=1$ in our model) of optimal income taxation.

8. A similar result is found in Hellwig (2010), but using a different argument in the tradition of Laroque (2004) and Kaplow (2006). Our result, apart from following the more well-known argument of Atkinson and Stiglitz (1976), is valid for both linear and nonlinear indirect taxes.

9. See, e.g., Atkinson and Stiglitz (1980), Myles (1995, pp. 163-6), and Salanié (2011, pp. 125-7), where one may check that the first-order conditions for incentive compatibility that are replaced in the equivalent equation to (16) are explicitly referred to linear indirect taxes.

\section{References}

Atkinson, A. B. and Stiglitz, J. E. (1976), “The design of tax structure: Direct versus indirect taxation”, Journal of Public Economics, 6: 55-75.

Atkinson, A. B. and Stiglitz, J. E. (1980), Lectures on Public Economics, London and New York: McGraw-Hill. 
Boadway, R. (2012), From optimal tax theory to tax policy: retrospective and prospective views, Munich Lectures in Economics. Cambridge, MA: MIT Press. Retrieved from http://www.jstor.org/stable/ j.ctt5vjpkx.

Boadway, R. and Pestieau, P. (2003), "Indirect taxation and redistribution: the scope of the Atkinson-Stiglitz theorem", in R. Kanbur and R. Arnott, R. (eds.), Imperfect Economics: Essays in Honor of Joseph Stiglitz, Cambridge, MA: The MIT Press, 387-403.

Boadway, R. and Song, Z. (2016), "Indirect taxes for redistribution: Should necessity goods be favored?", Research in Economics, 70(1): 64-88.

Browning, M. and Meghir, C. (1991), "The effects of male and female labour supply on commodity demands", Econometrica, 59(4): 925-951.

Christiansen, V. (1984), "Which commodity taxes should supplement the income tax?", Journal of Public Economics, 24: 195-220.

Coate, S. (2000), "An efficient approach to the evaluation of policy changes", Economic Journal, 110 (463): 437-455.

Corlett, W. J. and Hague, D. C. (1953), “Complementarity and the excess burden of taxation”, Review of Economic Studies, 21 (1): 21-30.

Crawford, I., Keen, M. and Smith, S. (2010), "Value added taxes and excises", in J. A. Mirrlees and S. Adam (eds.), Dimensions of Tax Design: The Mirrlees Review, T. J. Besley, R. Blundell, S. Bond, R. Chote, M. Gammie, P. Johnson, G. D. Myles, G. D. and J. M. Poterba, Oxford: Oxford University Press, 275-422.

Cremer, H., Pestieau, P. and Rochet, J. (2001), "Direct versus indirect taxation: the design of tax structure revisited", International Economic Review, 42: 781-799.

Edwards, I., Keen, M. and Tuomala, M. (1994), "Income tax, commodity taxes and public good provision: a brief guide", Finanzarchiv, 22: 472-487.

European Commission (2013), "Tax reforms in EU member states 2013”, European Economy, 5.

Gadenne, L. (2014), "Non-linear commodity taxation in developing countries: theory and an application to India", University College London and Institute for Fiscal Studies.

Gordon, R. H. and Kopczuk, W. (2014), "The choice of the personal income tax base”, Journal of Public Economics, 118: 97-110.

Hunt A., Lockwood, B. and Taubinsky, D. (2018), "Ramsey strikes back: optimal commodity taxes and redistribution in the presence of salience effects", NBER Working Paper, No. 24233 (http://www.nber. org/papers/w24233).

Hartline, J. (2012), "Bayesian mechanism design, foundations and trends", Theoretical Computer Science, 8(3): 143-263.

Hellwig, M. (2010), "A generalization of the Atkinson-Stiglitz (1976) theorem on the undesirability of nonuniform excise taxation”, Economics Letters, 108: 156-158.

International Monetary Fund (2014), "Fiscal Policy and Income Inequality", IMF Policy Paper 23, Washington DC: IMF.

Jacobs, B. and R. Boadway (2013), “Optimal linear commodity taxation under optimal non-linear income taxation", CESifo Working Paper: Public Finance, 4142. 
Two reasons for not using comodity taxation in the presence of an optimal income tax

Jacobs, B. and Boadway, R. (2014), "Optimal linear commodity taxation under optimal non-linear income taxation", Journal of Public Economics, 117: 201-210.

Kaplow, L. (2006), "On the undesirability of commodity taxation even when income taxation is not optimal", Journal of Public Economics, 90: 1235-1250.

Koehne, S. (2018), “Taxation of durable goods”, International Economic Review, 59(2): 825-857.

Laroque, G. (2005), "Indirect taxation is superfluous under separability and taste homogeneity: A simple proof”, Economic Letters, 87: 141-144.

Little, M. D. (1957), A critic of welfare economics, $2^{\text {nd }}$ Edition, Oxford.

Mirrlees, J. A. (1971), "An exploration in the theory of optimum income taxation”, Review of Economic Studies, 38: 175-208.

Mirrlees, J. A. (1975, 1999), "The theory of moral hazard and unobservable behaviour. Part I", Review of Economic Studies, 66: 3-22.

Mirrlees, J. A. (1976), “Optimal tax theory: a synthesis”, Journal of Public Economics, 7: 327-58.

Mirrlees, J. A. (1986), “The theory of optimal taxation”, in K. J. Arrow and M. D. Intriligator (eds.), Handbook of Mathematical Economics, Vol. 3, Amsterdam: Elsevier-North Holland, 1197-367.

Mirrlees, J. A., Adam, S., Besley, T. J., Blundell, R., Bond, S., Chote, R., Gammie, M., Johnson, P., Myles, G. D. and Poterba, J. M. (2011), Tax by Design: the Mirrlees Review, Oxford: Oxford University Press.

Myles, G. D. (1995), Public Economics, Cambridge, United Kingdom: Cambridge University Press.

Naito, H. (1999), "Re-examination of uniform commodity taxes under a non-linear income tax system and its implication for production efficiency", Journal of Public Economics, 71: 165-188.

Nava, M., Schroyen, F. and Marchand, M. (1996), "Optimal fiscal and public expenditure policy in a two-class economy”, Journal of Public Economics, 61: 119-137.

Nygård, O. E. (2014), “Optimal commodity taxation for Norway with cross-border shopping”, FinanzArchiv/Public Finance Analysis, 70: 316-342.

Pirttilä, J. and Suoniemi, I. (2014), "Public provision, commodity demand and hours of work: an empirical analysis", Scandinavian Journal of Economics, 116(4): 1044-1067.

Piketty, T. and Saez, E. (2013), "Optimal labor income taxation”, in Alan J. Auerbach, Raj Chetty, Martin Feldstein, and Emmanuel Saez (eds.), Handbook of Public Economics, Vol. 5, Amsterdam: Elsevier-North Holland, 391-474.

Pirttilä, J. and Tuomala, M. (1997), "Income tax, commodity tax and environmental policy”, International Tax and Public Finance, 4: 379-393.

Revesz, J. (2014), "A numerical model of optimal differentiated indirect taxation", Hacienda Pública Española/Review of Public Economics, 211 (4): 9-66.

Rochet, J. C. (1987), "A necessary and sufficient condition for rationalizability in a quasi-linear context”, Journal of Mathematical Economics, 16: 191-200.

Rochet, J. C. and Choné, P. (1998), “Ironing, sweeping, and multidimensional screening”, Econometrica, 66 (4): 783-826. 
Ruiz del Portal, X. (2012 a), "On the implementability of contracts without quasilinear utility", Economics Letters, 116(1): 42-45.

Ruiz del Portal, X. (2012 b), "Conditions for incentive compatibility in models with multidimensional allocation functions and one-dimensional types", Review of Economic Design, 16(4): 301-325.

Ruiz del Portal, X. (2012 c), "On the direct versus indirect tax controversy”, Hacienda Pública Española/Review of Public Economics, 203: 9-22.

Ruiz del Portal, X. (2017), "Optimal mixed taxation, public goods and the problem of high-skilled emigration”, Journal of Economics, 122 (2): 97-119.

Saez, E. (2002), "The desirability of commodity taxation under non-linear income taxation and heterogeneous tastes", Journal of Public Economics, 83: 217-230.

Salanié, B. (2011), The economics of taxation, Second edition, Cambridge, Mass.: MIT Press.

Seade, J. (1977), “On the shape of optimal tax schedules", Journal of Public Economics, 7: 203-235.

Stern, N. (1990), "Uniformity versus selectivity in indirect taxation", Economics and Politics, 2(1): 83-108.

\section{Resumen}

Este trabajo presenta dos argumentos a favor de un uso exclusivo del impuesto sobre la renta con fines redistributivos. El primero es el hecho de que la mayoría de resultados sobre imposición indirecta no lineal, tales como las fórmulas de Mirrlees para la eficiencia de Pareto, los resultados de Seade sobre tipos marginales zero en los extremos de la escala de renta, y la regla impositiva de Corlett y Hague solo resultan válidos bajo el enfoque de segundo orden con la poco realista función de utilidad lineal en relación a la capacidad individual. El segundo se centra en que, para que el teorema de Atkinson y Stiglitz resulte válido, es suficiente suponer que las preferencias son débilmente separables entre el consumo y la capacidad individual. Todo ello relega el uso de impuestos no lineales sobre el consumo al improbable escenario en que, aparte de preferencias no débilmente separables entre el consumo y la capacidad individual, existe una solución al problema planteado bajo el enfoque de primer orden.

Palabras clave: Impuestos sobre el consume no-lineales, enfoque de segundo-orden, teorema de Atkinson and Stiglitz.

Clasificación JEL: C6, D6, D8, H2. 